\title{
Perovskite oxides as transparent semiconductors: a review
}

\author{
Haiying $\mathrm{He}^{1}$, Zhihao Yang ${ }^{1 *}$, Yonghang $\mathrm{Xu}^{1}$, Andrew T. Smith ${ }^{2,3}$, Guangguang Yang ${ }^{4}$ and Luyi Sun ${ }^{2,3^{*}}$
}

\begin{abstract}
Traditional transparent conducting oxides (TCOs) have been widely used for various optoelectronic applications, but have the trade-off between conductivity and transmittance. Recently, perovskite oxides, with structural and chemical stability, have exhibited excellent physical properties as new TCOs. We focus on $\mathrm{SrVO}_{3}$-based perovskites with a high carrier concentration and $\mathrm{BaSnO}_{3}$-based perovskites with a high mobility for n-type TCOs. In addition, p-type perovskites are discussed, which can serve as potential future options to couple with $n$-type perovskites to design full perovskite based devices.
\end{abstract}

Keywords: Perovskite oxide, Transparent conducting oxide, $\mathrm{SrVO}_{3}, \mathrm{BaSnO}_{3}$, Semiconductor

\section{Introduction}

Transparent conducting oxides (TCOs) are a group of unique materials for optoelectronic applications, including displays, solar cells, and light-emitting diodes [1-4]. High transmittance $(\geq 80 \%)$ in the visible spectrum, high conductivity, and high carrier mobility are required for transparent electronics. Various metal oxide materials, such as Sn-doped $\operatorname{In}_{2} \mathrm{O}_{3}$ (ITO) [5-7], F-doped $\mathrm{SnO}_{2}$ (FTO) [8, 9], Sb-doped $\mathrm{SnO}_{2}$ (ATO) [10, 11], and Al-doped $\mathrm{ZnO}$ (AZO) [12-15], have been investigated. Researchers have been developing these oxides to exhibit high performance by focusing on transmittance in the visible range, electrical conductivity at room temperature, stability in the working environment, high carrier mobility, and controlling conductive type.

Electrical conductivity is determined by $\sigma=\mathbf{e n} \mu=\mathbf{e}^{2} \mathbf{\tau}$ $\left(\mathbf{n} / \mathbf{m}^{\prime \prime}\right)$, where $\mathbf{T}, \mathbf{n}$, and $\mathbf{m}^{\prime \prime}$ are scattering time, carrier concentration, and electron effective mass, respectively. It is clear that the value of $\mathbf{n} / \mathbf{m}^{*}$ is the key to achieve high performance of TCOs provided that the scattering time

\footnotetext{
*Correspondence: pvtech@qq.com; luyi.sun@uconn.edu

${ }^{1}$ School of Materials Science and Hydrogen Energy, Foshan University,

Foshan 528000, China

2 Polymer Program, Institute of Materials Science, University

of Connecticut, Storrs, CT 06269, USA

Full list of author information is available at the end of the article
}

is maximized [16]. Typical post-transition metal cations such as $\mathrm{In}^{3+}[7,17], \mathrm{Zn}^{2+}[18]$, and $\mathrm{Sn}^{4+}[19]$ have largely spread vacant s-orbitals to form the conduction band minimum (CBM) of TCOs, along with small effective masses. Among these materials, ITO has been widely used in industry thanks to its highest conductivity $\left(\sim 10^{4} \mathrm{~S} \cdot \mathrm{cm}^{-1}\right)$, along with an electron carrier concentration of the order of $10^{21} \mathrm{~cm}^{-3}[5,20]$. However, the carrier concentration is limited and the total scattering time of the carriers could be reduced due to the solubility limitation of the dopants as well as self-compensation [21-23]. Additionally, it is well-known that the markets for transparent devices are large but the critical raw material, Indium (In), is scarce on earth, which has led to high costs [24]. Substitution with $\mathrm{ZnO}$ - and $\mathrm{SnO}_{2}$-based binary compounds has found success with optimized electrical performance, but this strongly depends on approaches of deposition and growing conditions [25]. It should be noted that it is difficult to deposit high performance impurity-doped metal oxide thin films. The key factors are to improve crystallinity by deposition methods and control an oxidizing atmosphere [25-27]. It was reported that AZO thin films deposited by pulsed laser deposition (PLD) showed an encouraging conductivity of the order of $10^{4} \mathrm{~S} \cdot \mathrm{cm}^{-1}$ [15].

Carrier mobility $(\boldsymbol{\mu})$, defined as $\boldsymbol{\mu}=\mathbf{e} \mathbf{\tau} / \mathbf{m}^{*}$, is another important factor for the high performance of transparent 
oxides. Conduction bands derived from widely spread metal $\mathrm{s}$ orbitals result in n-type conductivity and thus excellent electron carrier mobility, whose values range from 10 to $100 \mathrm{~cm}^{2} \cdot \mathrm{V}^{-1} \cdot \mathrm{s}^{-1}$. However, the applications of transparent oxides can hardly be further developed due to the lack of $\mathrm{p}$-type counterparts for $\mathrm{p}$-n heterojunctions $[20,28,29]$ or other p-type devices like photovoltaics [3]. So far no efficient method has been created to introduce shallow acceptors and small hole effective mass due to strongly localized $\mathrm{O} 2 \mathrm{p}$ orbital derived from valence bands of metal oxides, though huge efforts have been made [30]. The carrier mobility of p-type TCOs cannot compare with those of $\mathrm{n}$-type, even though high mobility values have been achieved from $\mathrm{Cu}$-based materials [31, 32] at the sacrifice of hole carrier concentration.

$\mathrm{ABO}_{3}$-based perovskite oxides are common in inorganic compounds. The ideal cubic perovskite structure $(P m-3 m)$ is composed of an A-site cation (an alkalineearth, a rare-earth or an alkali element), B-site cation (a transition or post-transition metal element from periods 4,5 , or 6 in the periodic table), and oxygen anions. B-site cation sits at the center of $\mathrm{BO}_{6}$ octahedron [65]. It should be noted that distortions are caused by cations of different radii, which results in octahedral tilting. The structure of perovskite oxides can remain stable even if A- or B-site cations are replaced by a large amount of other elements [33, 34]. Materials with a perovskite structure have drawn high attention for extensive research on a variety of physical properties, including superconductivity [35], metal-insulator transition [36], photovoltaic effect [37], transparent conductivity [38-43], magnetism [44], and ferroelectricity [37, 45]. In particular, using novel perovskite oxides to replace traditional binary TCO materials has become popular. Recently, Zhang et al. [16] reported that correlated metal compounds (e.g., $\mathrm{SrVO}_{3}$ and $\mathrm{CaVO}_{3}$ ), as transparent conductors, had an excellent carrier concentration $\left(>2.2 \times 10^{22} \mathrm{~cm}^{-3}\right)$, an order of magnitude greater than that of ITO $\left(\sim 10^{21} \mathrm{~cm}^{-3}\right)$. Alkaline earth stannates $\left(\mathrm{ASnO}_{3}, \mathrm{~A}=\mathrm{Ca}, \mathrm{Sr}, \mathrm{Ba}\right)$ have a wide bandgap $(\sim 3.0 \mathrm{eV})$, exhibiting highly transparent visible photovoltaic effective range and excellent electrical properties [46-50], i.e., a mobility up to $320 \mathrm{~cm}^{2} \cdot \mathrm{V}^{-1} \cdot \mathrm{s}^{-1}$ at room temperature $[51,52]$. In contrary to stoichiometric perovskite oxides that are insulating, oxygen-deficient structures transform to semiconductor or conductor, i.e., oxygen vacancy also plays a role in electrical properties $[53,54]$. Early research results have revealed high thermal stability of oxygen in perovskite materials $[55,56]$, thus avoiding the degradation in the oxide-based electronic devices.

On the other hand, it remains a challenge to achieve p-type conductivity by binary post-transition metal oxide because of strongly localized $\mathrm{O} 2 \mathrm{p}$ orbitals, resulting in high formation energy of acceptor and large hole carrier masses. Fortunately, A or B sites can easily be replaced by other elements in perovskite oxides, thanks to the high chemical and structural stability. Stoichiometric strontium titanate $\left(\mathrm{SrTiO}_{3}, \mathrm{STO}\right)$ is a group of highly transparent insulators $(\mathrm{Eg} \sim 3.2 \mathrm{eV})$ that can be easily doped by $\mathrm{Nb}$ [57], $\mathrm{La}$ [58], or Sb [59] for n-type STO, or doped by Sc [60], and In [61] for p-type ones. Like "chemical modulation of the valence band" (CMVB), introduced by Hosono et al., partial replacement of $\mathrm{Al}$ for $\mathrm{Sn}$ in cubic perovskite-structures, $\mathrm{SrSnO}_{3}$, can decrease the localization and generate holes in the valence [62]. Perovskite compounds such as $\mathrm{La}_{1-\mathrm{x}} \mathrm{AlSnO}_{3}$ [62], $\mathrm{La}_{1-\mathrm{x}} \mathrm{Sr}_{\mathrm{x}} \mathrm{CrO}_{3}$ [42, 63], $\mathrm{La}_{2 / 3} \mathrm{Sr}_{1 / 3} \mathrm{VO}_{3}$ [33], $\mathrm{SrTiO}_{3}: \mathrm{Rh}$ [64], etc., can be p-type TCO candidates, which demonstrate excellent electrical and optical properties. The new perovskite oxides not only balance the trade-off between conductivity and transmittance, but also show p-type characteristics. Development of p-type perovskite oxides are critical, along with n-type perovskites, to make full perovskite devices.

In this article, we review the novel TCO materials based on perovskite oxides. Section 2 discusses the crystal structure, electronic properties, fabrication methods of the $\mathrm{SrVO}_{3}$ - and $\mathrm{BaSnO}_{3}$-based perovskites. $\mathrm{SrVO}_{3}$ films inherit a high conductivity thanks to the high carrier concentration, even though they have a high effective mass. $\mathrm{BaSnO}_{3}$-based perovskites have a high mobility. Section 3 describes the properties and impurity doping of p-type perovskite oxides. Due to their high chemical stability, perovskite oxides can be doped with A- or B-site.

\section{2 n-Type perovskites}

\section{1 $\mathrm{SrVO}_{3}$}

Alkaline earth metal vanadium oxides with the $\mathrm{AVO}_{3}$ $(\mathrm{A}=\mathrm{Ca}, \mathrm{Sr}, \mathrm{Ba})$ composition have a $\mathrm{V}^{4+} 3 \mathrm{~d}^{1}$ electronic configuration with a single electron in the partially filled $t_{2 g}$ band. The first-principle calculations showed three $t_{2 g}$ bands at the Fermi energy between $-1.5 \mathrm{eV}$ and $1.5 \mathrm{eV}$ [66]. In this article, strontium vanadium oxide $\left(\mathrm{SrVO}_{3}\right.$, SVO), which has aroused widespread interest, is selected to illustrate that strongly correlated metal oxides are promising transparent conductive materials. SVO possesses cubic symmetry $(a=3.842 \AA)$ with one $V$ atom surrounded by six $\mathrm{O}$ atoms to form an octahedral configuration (Fig. 1a). The valence band maximum (VBM) is composed of $\mathrm{O} 2 \mathrm{p}$ orbitals, and the conduction band minimum $(\mathrm{CBM})$ is composed of $\mathrm{V} 3 \mathrm{~d}$ orbitals that can be split into $e_{\text {g. }}$ and $t_{2 g}$ states (Fig. $1 b$ ). The width of $3 \mathrm{~d}$ bands is narrow enough $(\mathrm{W} \approx 2-3 \mathrm{eV}$ ) so that the local Coulomb interaction between the electrons is particularly strong, causing electronic correlations [67]. 

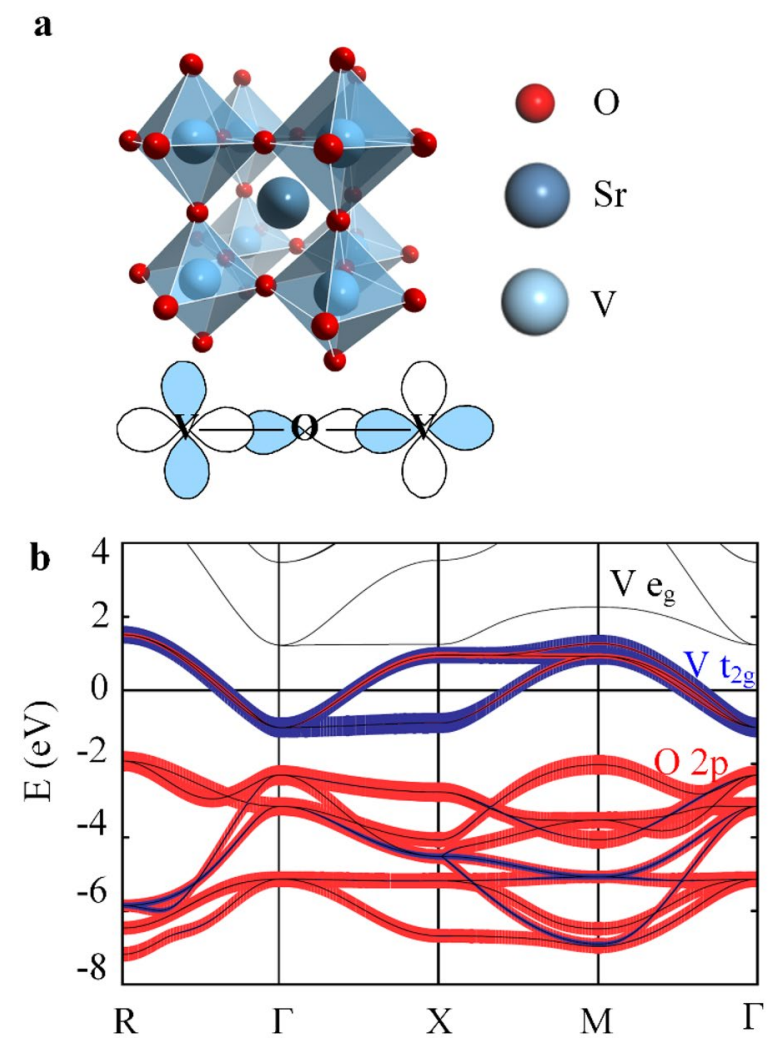

Fig. 1 a Cubic perovskite structure of $\mathrm{SrVO}_{3}(\mathrm{a}=3.842 \AA)$. b Band structure of $\mathrm{SrVO}_{3}$ in the vicinity of the Fermi level $\mathrm{E}_{\mathrm{F}}$ [68]

SVO is an important strongly correlated metal oxide that has been extensively investigated in both theoretical [68-70] and experimental researches [71-73]. Recently, SVO has been reported as a transparent conductor because of its high electrical properties. Contrary to heavy doping to optimize physical properties in widebandgap semiconductors, Zhang et al. [16] demonstrated that novel materials with strong electron-electron interactions had a higher carrier concentration in comparison with that of ITO. This kind of materials inherit a high conductivity $\left(\sim 10^{4} \mathrm{~S} \cdot \mathrm{cm}^{-1}\right)$ due to the higher carrier concentration $\left(\sim 10^{22} \mathrm{~cm}^{-3}\right)$ although they have a high effective mass. In addition, SVO films show optical transmittance in the visible range due to lower plasma frequency $\left(\omega_{\mathrm{p}}{ }^{*}=1.33 \mathrm{eV}\right)$, allowing them to be thinner, to increase optical transmittance in the visible spectrum range without suffering from surface scattering because of the much smaller electron mean free path $\left(\mathrm{EMFP}=\hbar\left(3 \pi^{2}\right)^{1 / 3}\left(\mathrm{\tau} / \mathrm{n}^{2 / 3}\right)\left(\mathrm{n} / \mathrm{m}^{*}\right)\right)$ in correlated metal oxides $\left(\mathrm{SrVO}_{3}, \mathrm{EMFP}=5.6 \mathrm{~nm}\right.$ and $\mathrm{CaVO}_{3}$, $\mathrm{EMFP}=3.9 \mathrm{~nm}$ ) [16] than other conductors, like $\mathrm{Ag}$ $(\mathrm{EMFP}=52 \mathrm{~nm})$ and $\mathrm{Au}(\mathrm{EMFP}=50 \mathrm{~nm})[74,75]$.

However, an inevitable problem is that the carrier mobility and transmittance of SVO is lower than ITO. The factors those affect the physical properties of the SVO thin films, including: (1) Film crystallinity. The SVO thin films with high performance are all crystal phase deposited on lattice-matching substrates, such as $\left(\mathrm{LaAlO}_{3}\right)_{0.3}\left(\mathrm{Sr}_{2} \mathrm{AlTaO}_{6}\right)_{0.7}$ (LSAT), $\mathrm{SrTiO}_{3}$ (STO), $\mathrm{NdGaO}_{3}$ (NGO), etc., as shown in Table 1, instead of on an amorphous substrate (glass or PET) or other substrates with a different crystal structure $(\mathrm{Si}, \mathrm{GaN}$, or $\mathrm{Al}_{2} \mathrm{O}_{3}$ ). Note that the properties of the films are not directly affected by the lattice mismatch, but mainly determined by lattice misfit between the SVO film $(\mathrm{a}(\mathrm{SVO}))$ and the substrate $\left(\mathrm{a}_{\mathrm{s}}\right), f=\left[\mathrm{a}_{\mathrm{s}}-\mathrm{a}(\mathrm{SVO})\right] /$ $\mathrm{a}_{\mathrm{s}}$. The $f$ values between SVO bulk and LSAT (3.868 $\AA)$, STO (3.905 $\AA$ ), and NGO (3.863 $\AA$ ) substrates are $+0.67 \%,+1.61 \%$, and $+0.54 \%$, respectively. Under the same growth conditions, the carrier concentration (or mobility) of the SVO films on LSAT and NGO are close, with values of $2.14 \times 10^{22} \mathrm{~cm}^{-3}\left(2.9 \mathrm{~cm}^{2} \cdot \mathrm{V}^{-1} \cdot \mathrm{s}^{-1}\right)$ and $2.2 \times 10^{22} \mathrm{~cm}^{-3}\left(3.3 \mathrm{~cm}^{2} \cdot \mathrm{V}^{-1} \cdot \mathrm{s}^{-1}\right)$, respectively [76]. However, the resistivity of the SVO film grown on an LSAT substrate $(70 \mu \Omega \cdot \mathrm{cm})$ is lower than that on

Table 1 Summary of the electrical properties of $\mathrm{SrVO}_{3}$ thin films compared to ITO

\begin{tabular}{|c|c|c|c|c|c|}
\hline Substrate & Deposit methods & $\begin{array}{l}\text { Mobility } \\
\mathrm{cm}^{2} \cdot \mathrm{V}^{-1} \cdot \mathrm{s}^{-1}\end{array}$ & $\begin{array}{l}\text { Carrier concentration } \\
\mathrm{cm}^{-3}\left(\times 10^{22}\right)\end{array}$ & $\begin{array}{l}\text { Resistivity } \Omega \cdot \mathrm{cm} \\
\left(\times 10^{-5}\right)\end{array}$ & Ref. \\
\hline $\mathrm{Sn}: \mathrm{In}_{2} \mathrm{O}_{3}$ (ITO) On glass substrate & Reactive e-beam evaporation & $\sim 30$ & 0.08 & $\sim 0.2$ & {$[6]$} \\
\hline $\mathrm{SrTiO}_{3}(\mathrm{STO})$ & PLD & 1.35 & 2.48 & 0.187 & [78] \\
\hline$\left(\mathrm{LaAlO}_{3}\right)_{0.3}\left(\mathrm{Sr}_{2} \mathrm{AlTaO}_{6}\right)_{0.7}(\mathrm{LSAT})$ & MBE & $\sim 10^{\mathrm{a}}$ & 2.26 & 2.8 & [16] \\
\hline$\left(\mathrm{LaAlO}_{3}\right)_{0.3}\left(\mathrm{Sr}_{2} \mathrm{AlTaO}_{6}\right)_{0.7}(\mathrm{LSAT})$ & Hybrid-MBE & $\sim 9^{\mathrm{a}}$ & - & 3 & [43] \\
\hline $\mathrm{NdGaO}_{3}(\mathrm{NGO})$ & PLD & 8.3 & 2.4 & 3 & [76] \\
\hline$\left(\mathrm{LaAlO}_{3}\right)_{0.3}\left(\mathrm{Sr}_{2} \mathrm{AlTaO}_{6}\right)_{0.7}(\mathrm{LSAT})$ & PLD & $\sim 7^{\mathrm{a}}$ & 2.6 & 3.8 & {$[76]$} \\
\hline$\left(\mathrm{LaAlO}_{3}\right)_{0.3}\left(\mathrm{Sr}_{2} \mathrm{AlTaO}_{6}\right)_{0.7}(\mathrm{LSAT})$ & PLD & 3.05 & 2.18 & $0.12 \sim 0.19$ & {$[80]$} \\
\hline$\left(\mathrm{LaAlO}_{3}\right)_{0.3}\left(\mathrm{Sr}_{2} \mathrm{AlTaO}_{6}\right)_{0.7}(\mathrm{LSAT})$ & MBE & 8.7 & 2.3 & 3.2 & [81] \\
\hline$\left(\mathrm{LaAlO}_{3}\right)_{0.3}\left(\mathrm{Sr}_{2} \mathrm{AlTaO}_{6}\right)_{0.7}(\mathrm{LSAT})$ & Sputtering & 1.82 & 1.57 & 0.2 & [84] \\
\hline
\end{tabular}

a Values estimated graphically 
a STO substrate $(90 \mu \Omega \cdot \mathrm{cm})$ [77]. (2) Growing methods. To grow high quality thin films, various growing methods have been developed to deposit SVO films to achieve high performance, including pulsed laser deposition (PLD) [76-80], molecular beam epitaxy (MBE) [81], hybrid MBE [43, 82, 83], and radio frequency sputtering deposition (RF sputtering) [84]. These results show that preparation method has a great influence on the properties of the prepared films. This might be caused by the defects generated in the preparation process. For example, good stoichiometric $\mathrm{SrVO}_{3}$ can be controlled by hybrid $\mathrm{MBE}$, which can reduce the number of defects of perovskite-based oxide films [82, 83]. The resistivity $(28 \mu \Omega \cdot \mathrm{cm}[16])$ of the SVO films grown by MBE measured at room temperature is lower than those grown by other deposition approaches like PLD (38 [79] and $120 \mu \Omega \cdot \mathrm{cm}$ [80]).

An open question still facing SVO materials is if it will be one of the candidates to replace ITO in many optoelectronic devices. Except for high optical transmittance and high electrical properties, large area deposition, uniformity, and integration of oxide materials are essential. Amorphous materials have obvious advantages in the deposition of large area homogeneous films thanks to their anisotropy properties. Boileau et al. [80] investigated the optical and electrical properties of SVO films without long-range crystalline order. The resistivity and transmittance were found to depend on crystalline state. In the crystalline state, the transmittance reached ca. $80 \%$ for a $520 \mathrm{~nm}$ film and the resistivity was measured to be $1.2 \sim 1.9 \times 10^{-4}$ $\Omega \cdot \mathrm{cm}$, while the electrical properties deceased sharply with a decreasing crystallinity and the resistivity increased by orders of magnitude. The crystallinity of SVO significantly affects the properties of the films, limiting their potential as an alternative to ITO. Besides, the mobility of carriers is low due to the high effective mass induced by strong electron-electron interaction.

Furthermore, the performance of SVO thin films is sensitive to oxygen pressure $[77,79,85]$. In general, $\mathrm{SVO}$ is grown under low oxygen pressure, which is different from other strongly correlated perovskite materials, such as $\mathrm{LaNiO}_{3}$ and $\mathrm{SrRuO}_{3}$ grown under high oxygen pressure conditions [86-88]. At a high oxygen pressure, $\mathrm{V}^{4+}$ can be easily oxidized into $\mathrm{V}^{5+}$, indicating that optimization of oxygen pressure has a positive effecnt on film properties. It should be noted that the properties of the films prepared in vacuum are not optimal $[77,79]$. Wang et al. achieved the highest conductivity at room temperature with an oxygen pressure of $1 \times 10^{-5}$ mbar [77]. The effect of oxygen pressure on

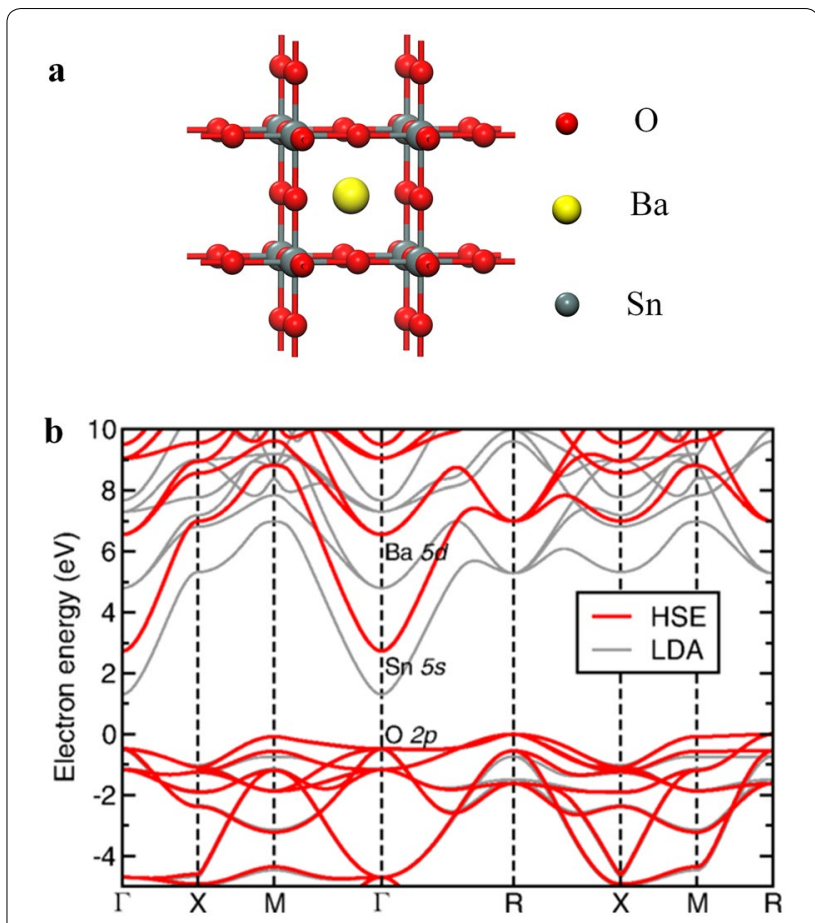

Fig. 2 a Cubic perovskite structure of $\mathrm{BaSnO}_{3}(\mathrm{a}=4.115 \AA$ ). $\mathbf{b}$ Band structure of $\mathrm{BaSnO}_{3}$ based on the first-principle calculations [102]

the physical properties of thin films is still not completely clear and requires further investigation.

\section{2 $\mathrm{BaSnO}_{3}$}

\subsubsection{Theoretical calculation}

The limitation of SVO films for wide applications is their low carrier mobility, which is just on the order of $10 \mathrm{~cm}^{2} \cdot \mathrm{V}^{-1} \cdot \mathrm{s}^{-1}$. It is difficulty to enhance the mobility because of high effective mass and anisotropic electron carrier transport path. In contrast to strongly correlated SVO, alkaline earth stannates $\left(\mathrm{ASnO}_{3}, \mathrm{~A}=\mathrm{Ba}\right.$, $\mathrm{Sr}$, and $\mathrm{Ca}$ ) have been reported to have a high mobility, particularly barium stannate $\left(\mathrm{BaSnO}_{3}\right)$. Unlike V 3d, Sn 5 s orbitals are isotropic and can still overlap to a large extent even in the amorphous state, without affecting the conductivity. Metal ions with $(n-1)$ $\mathrm{d}^{10} \mathrm{~ns}^{0}$ electronic configuration play a dominant role in high conductivity and high mobility of amorphous semiconductor materials $[89,90]$. According to the literature, $\mathrm{BaSnO}_{3}$ (belonging to the perovskite family), shows a wide band gap $\left(E_{g}>3.1 \mathrm{eV}\right)$ [91], a high thermal stability [55], and a high carrier mobility up to $320 \mathrm{~cm}^{2} \cdot \mathrm{V}^{-1} \cdot \mathrm{s}^{-1}$ in single crystals at room temperature [51] and $70 \mathrm{~cm}^{2} \cdot \mathrm{V}^{-1} \cdot \mathrm{s}^{-1}$ in epitaxial films [52], respectively. Caused by the high mobility, $\mathrm{BaSnO}_{3}$-based materials have been used as a semiconductor layer in oxide thin film transistors (TFTs) [92-95] and other 
photoelectronic devices [96-98]. It should be mentioned that the mobility of $\mathrm{BaSnO}_{3}$ is much higher than that of $\mathrm{SrVO}_{3}$. In contrast to CBM derived mainly from the localized V 3d states, the first-principle calculations showed that CBM is dominated by dispersive $\mathrm{Sn}$ $5 \mathrm{~s}$ states (Fig. 2), leading to a smaller carrier effective mass $[48,99]$. This is similar to other cations with a $(\mathrm{n}-1) \mathrm{d}^{10} \mathrm{~ns}^{0}$ electron configuration, such as $\mathrm{In}^{3+}, \mathrm{Zn}^{2+}$, and $\mathrm{Ga}^{3+}$. Most effective masses of $\mathrm{BaSnO}_{3}$ from the first-principle calculations are between 0.2 and $0.5 \mathrm{~m}_{0}$ $[38,48,96,100,101]$. They are apparently smaller than titanium- or vanadium-based perovskites, e.g., $\mathrm{BaTiO}_{3}$ $\left(5.3 \mathrm{~m}_{0}\right)$ [103], and $\mathrm{SrVO}_{3}\left(3.0 \mathrm{~m}_{0}\right)$ [76], but close to traditional semiconductors, such as $\mathrm{Si}\left(0.27 \mathrm{~m}_{0}\right)$ [104], $\mathrm{In}_{2} \mathrm{O}_{3}\left(0.35 \mathrm{~m}_{0}\right)$ [25], and $\mathrm{SnO}_{2}\left(0.25 \mathrm{~m}_{0}\right)$ [105]. The smallest value below $0.03 \mathrm{~m}_{0}$ was reported by Moreira et al. with first-principle local density approximation (LDA) and generalized gradient approximations (GGA) calculations [106]. The small effective mass has been found in tin-based perovskites [48], including $\mathrm{SrSnO}_{3}$ $\left(0.23 \mathrm{~m}_{0}\right), \mathrm{ZnSnO}_{3}\left(0.17 \mathrm{~m}_{0}\right)$, and $\mathrm{CdSnO}_{3}\left(0.23 \mathrm{~m}_{0}\right)$. This indicates that cation Sn on B-site is critical to high mobility.

\subsubsection{Crystalline $\mathrm{BaSnO}_{3}$}

High mobility has not been measured for stoichiometric $\mathrm{BaSnO}_{3}$ and it is known that it is not caused by intrinsic defects, but obtained from La-doped $\mathrm{BaSnO}_{3}$. Negative defect formation energy indicates a high concentration of substituting $\mathrm{La}$ for $\mathrm{Ba}\left(\mathrm{La}_{\mathrm{Ba}}\right)$ in $\mathrm{BaSnO}_{3}$ [107], while the charge-state transition energy level, $\mathrm{E}\left[\mathrm{La}_{\mathrm{Ba}}(+/ 0)\right]$, with respect to $C B M$ is just $0.046 \mathrm{eV}$, indicating $\mathrm{La}_{\mathrm{Ba}}$ to be a shallow donor, which contributes one electron easily by the ionization of La atoms [48]. To be a good candidate for TCOs, the solubility of dopants should be high and the donor level should be shallow. High carrier mobility of $\mathrm{Ba}_{1-\mathrm{x}} \mathrm{La}_{\mathrm{x}} \mathrm{SnO}_{3}(\mathrm{x}=0$ to 0.04 ) crystals were reported by Luo et al., when $x=0.02$ the highest mobility was about $103 \mathrm{~cm}^{2} \cdot \mathrm{V}^{-1} \cdot \mathrm{s}^{-1}$ corresponding to a carrier concentration of $\sim 8-10 \times 10^{19} \mathrm{~cm}^{-3}$ [108]. Kim et al. [51] enhanced the carrier mobility of $(\mathrm{Ba}, \mathrm{La}) \mathrm{SnO}_{3}$ single crystals to the highest value so far of $320 \mathrm{~cm}^{2} \cdot \mathrm{V}^{-1} \cdot \mathrm{s}^{-1}$. In the crystal structure of $\mathrm{BaSnO}_{3}$, tin atom is at the center of the octahedra $\left(\mathrm{SnO}_{6}\right)$ and the band angle of $\mathrm{Sn}-\mathrm{O}-\mathrm{Sn}$ is $\sim 180^{\circ}$. When $\mathrm{Ba}$ is partially replaced by $\mathrm{La}$, the defects $\left(\mathrm{La}_{\mathrm{Ba}}\right)$ are located away from $\mathrm{SnO}_{6}$ octahedra, causing a low disorder effect. In addition, at a doping concentration of $8 \times 10^{19} \mathrm{~cm}^{-3}$, the mobility showed the highest value [51]. For single crystals, the mobility decreases with an increasing carrier concentration due to scattering. Therefore, a suitable doping level can reduce the dopant scattering in comparison with high carrier concentrations $\left(>10^{20} \mathrm{~cm}^{-3}\right)$. Phonon scattering also has an effect on carrier mobility, but such effect is less significant than that of dopant scattering.

\subsubsection{Epitaxy-grown $\mathrm{BaSnO}_{3}$ films}

Compared to single crystals, the mobility value of La-doped $\mathrm{BaSnO}_{3}$ epitaxial films is much lower due to grain boundaries and dislocations caused by lattice mismatch between $(\mathrm{Ba}, \mathrm{La}) \mathrm{SnO}_{3}$ and the substrate [109]. To enhance the film mobility, researchers managed to grow La-doped $\mathrm{BaSnO}_{3}$ epitaxial films on other cubic perovskites, such as $\mathrm{SrTiO}_{3}(001)[51,52,110]$, $\mathrm{SmScO}_{3}(110)$ [111], $\operatorname{PrScO}_{3}(110)$ [112], $\mathrm{TbScO}_{3}(110)$ [113], and $\mathrm{DyScO}_{3}(001)$ [114]. The electron mobility was enhanced from 5.8 to $183 \mathrm{~cm}^{2} \cdot \mathrm{V}^{-1} \cdot \mathrm{s}^{-1}$ at room temperature, as shown in Fig. 3. Furthermore, $\mathrm{BaSnO}_{3}$ epitaxial films were grown on $\mathrm{BaSnO}_{3}$ single crystal substrate with a mobility of $102 \mathrm{~cm}^{2} \cdot \mathrm{V}^{-1} \cdot \mathrm{s}^{-1}$ [115]. The mobility can be increased from $\sim 37 \mathrm{~cm}^{2} \cdot \mathrm{V}^{-1} \cdot \mathrm{s}^{-1}$ (without buffer) to $\sim 56 \mathrm{~cm}^{2} \cdot \mathrm{V}^{-1} \cdot \mathrm{s}^{-1}$ at room temperature when a bilayer of $\mathrm{BaSnO}_{3} /(\mathrm{Sr}, \mathrm{Ba}) \mathrm{SnO}_{3}$ was inserted as a buffer layer to reduce dislocation scattering [116]. Wang et al. [117] reported that La-doped $\mathrm{BaSnO}_{3}$ films using $\mathrm{SrTiO}_{3}$ buffer on $\mathrm{Si}(001)$ substrate showed a mobility of $128 \mathrm{~cm} \cdot \mathrm{V}^{-1} \cdot \mathrm{s}^{-1}$ at room temperature. This result is remarkable, but the fabrication cost has been significantly increased. To address this issue, Sanchela et al. [118] developed to grow La-doped $\mathrm{BaSnO}_{3}$ films under a highly oxidative ozone $\left(\mathrm{O}_{3}\right)$ atmosphere, achieving a balance between mobility $\left(115 \mathrm{~cm}^{2} \cdot \mathrm{V}^{-1} \cdot \mathrm{s}^{-1}\right)$ and processing cost.

\subsubsection{Oxygen vacancy}

The intrinsic point defect, oxygen vacancy $\left(\mathrm{V}_{\mathrm{O}}\right)$, plays a crucial role in various oxide semiconductors, including $\mathrm{ZnO}, \mathrm{SnO}_{2}$, and $\mathrm{In}_{2} \mathrm{O}_{3}$. The first-principle calculated results show that the formation energy of $\mathrm{V}_{\mathrm{O}}$ has a negative value in perovskite stannates [107], indicating defects will form spontaneously along with grown films. $\mathrm{BaSnO}_{3}$ films with a high oxygen vacancy concentration were fabricated at low oxygen pressures [54, $119]$ and reducing conditions (Ar containing 5\% $\mathrm{H}_{2}$ gas) [120]. Oxygen vacancies are donor defects which could contribute twice as many electron carriers per single-unit defect. Experimentally, high n-type carrier concentrations have been reported under $\mathrm{O}$-poor growth conditions [54, 121, 122]. Son and coworker [123] reported that the mobility of La-doped $\mathrm{BaSnO}_{3}$ film was $78 \mathrm{~cm}^{2} \cdot \mathrm{V}^{-1} \cdot \mathrm{s}^{-1}$ at room temperature by hightemperature annealing under a $\mathrm{N}_{2}$ environment to generate $\mathrm{V}_{\mathrm{O}}$. Later, the same group enhanced the mobility 

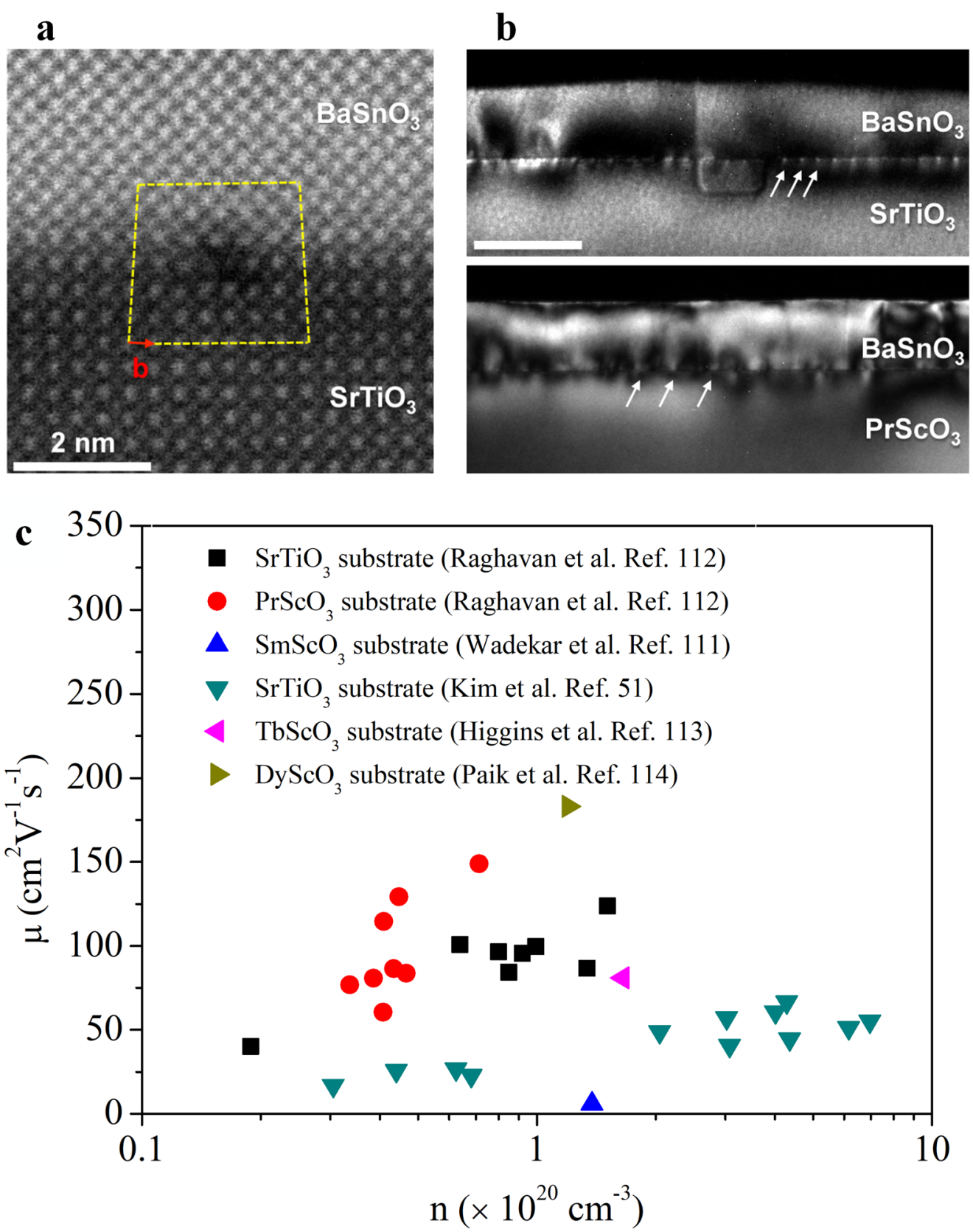

Fig. 3 a High-angle annular dark-field (HAADF)-STEM image of $\mathrm{BaSnO}_{3} / \mathrm{SrTiO}_{3}$ interface [1 12]. b Cross section dark-field TEM images of BaSnO ${ }_{3}$ on $\mathrm{SrTiO}_{3}$ (top) and $\mathrm{PrScO}_{3}$ substrates (bottom) [112]. c Summary of the mobility of $\mathrm{BaSnO}_{3}$ epitaxial films grown on $\mathrm{SrTiO}_{3}$ [51, 112], $\mathrm{SmScO}_{3}$ [111], $\mathrm{PrSCO}_{3}[112], \mathrm{TbSCO}_{3}[113]$, and $\mathrm{DySCO}_{3}[114]$ substrates

up to $122 \mathrm{~cm}^{2} \cdot \mathrm{V}^{-1} \cdot \mathrm{s}^{-1}$ by controlling the oxygen pressure using $\mathrm{H}_{2}$ environment annealing [120]. In addition, it is known that oxygen vacancies could be generated by a vacuum annealing process in undoped $\mathrm{BaSnO}_{3}$ films [124, 125]. Vacuum annealing methods have been reported to treat La-doped $\mathrm{BaSnO}_{3}$ films on $\mathrm{MgO}$ substrates with a carrier mobility of $101.6 \mathrm{~cm}^{2} \cdot \mathrm{V}^{-1} \cdot \mathrm{s}^{-1}$. The value was larger than that of the film deposited without annealing $\left(\sim 74 \mathrm{~cm}^{2} \cdot \mathrm{V}^{-1} \cdot \mathrm{s}^{-1}\right)$ [126]. Therefore, it is important to investigate the effect of oxygen vacancies on physical properties of $\mathrm{BaSnO}_{3}$ films. 


\section{3 p-Type perovskites}

Conventional TCOs, including $\mathrm{ZnO}, \mathrm{SnO}_{2}$, and $\mathrm{In}_{2} \mathrm{O}_{3}$, typically exhibit n-type electronic conductivity, and are widely used in various fields. However, the lack of high performance p-type TCOs has limited their applications $[127,128]$. In general, p-type TCOs were synthesized by acceptor doping to create holes in the valence band, but the hole concentration is usually not high enough due to recombination and strong localization $[129,130]$. The conductivity and hole concentration suffer from doping bottlenecks, intrinsic defects, and the solubility limit of the acceptors. Although previous studies explored some approaches to change n-type TCOs to p-type ones, the hole carrier mobility is usually an order of magnitude lower than that of electron carrier. Moreover, $\mathrm{Cu}^{+}$-based oxides $\left(\mathrm{CnMO}_{2}, \mathrm{M}=\mathrm{B}, \mathrm{Al}, \mathrm{Ga}\right.$, In, Sc) with $\mathrm{d}^{10}$ configuration were used for intrinsically p-type doped materials [131]. Layered oxychalcogenides [132] and $d^{6}$ spinel oxides [133] were reported to achieve p-type conductivity.

Due to their high chemical stability, $\mathrm{ABO}_{3}$-based perovskite transition metal oxides are of great interest in p-type materials. Even with A- or B-site doping, it is still stable for perovskite structures. Lanthanide-based perovskite $\mathrm{LaRhO}_{3}$ (LRO) with A-site doping (substituting $\mathrm{La}$ for $\mathrm{Sr}$ or $\mathrm{Ca}$ ) was reported as a candidate for p-type semiconductors [134]. Nakamura et al. [135] reported a p-type single-crystalline LRO semiconductor and investigated the physical properties of a heterojunction, which was comprised of n-type $\mathrm{Nb}: \mathrm{SrTiO}_{3}$. The bandgap of p-type LRO was just $1.3 \mathrm{eV}$, as shown Fig. 4.

In comparison with $\mathrm{Cu}^{+}$-based p-type oxides, the localization of $\mathrm{O} 2 \mathrm{p}$ orbitals is reduced from hybridization with metal d orbitals using a method called "chemical modulation of the valence band" (CMVB) [136]. The correlated metal oxides, $\mathrm{Cr}_{2} \mathrm{O}_{3}, \mathrm{~V}_{2} \mathrm{O}_{3}, \mathrm{LaCrO}_{3}, \mathrm{LaVO}_{3}$, and $\mathrm{LaCoO}_{3}$, were identified to be p-type TCOs [33, 42, 137-139]. The VB consists of a hybridization between
O $2 p$ orbitals and transition metal $3 \mathrm{~d}$ orbitals, leading to a reduction of the hole localization at the top of VB. In A-site doped perovskites $\mathrm{LaBO}_{3}(\mathrm{~B}=\mathrm{V}, \mathrm{Cr}, \mathrm{Co})$, the holes at the top of valence band (VB) could be introduced by replacing $\mathrm{Sr}^{2+}$ for $\mathrm{La}^{3+}$. Zhang et al. [42] grew a new p-type $\mathrm{Sr}$-doped $\mathrm{LaCrO}_{3}$ on $\mathrm{SrTiO}_{3}$ substrate by molecular beam epitaxy. The conductivity was up to $\sim 50 \mathrm{~S} \mathrm{~cm}^{-1}$ due to a high hole carrier concentration of $7.5 \times 10^{21} \mathrm{~cm}^{-3}$. In the periodic table, $\mathrm{V}$ element is located to the left side of $\mathrm{Cr}$. Therefore, the size of the $3 \mathrm{~d}$ wavefunction of $\mathrm{V}^{3+}$ is expanded, resulting in a smaller $\mathrm{U}$ ( $d-d$ Coulomb repulsion energy) in $\mathrm{LaVO}_{3}$ than that of $\mathrm{LaCrO}_{3}$ [140]. The conductivity of p-type $\mathrm{La}_{2 / 3} \mathrm{Sr}_{1 / 3} \mathrm{VO}_{3}$ (LSVO) films was enhanced to nearly $900 \mathrm{~S} \cdot \mathrm{cm}^{-1}$ at room temperature [33]. Meanwhile, the films exhibited a high transmittance up to $70 \%$, indicating that they possess the potential to be a high performance p-type TCO. Takashima et al. [139] grew p-type $\mathrm{La}_{0.67} \mathrm{Sr}_{0.33} \mathrm{CoO}_{3}$ films on a $\mathrm{SrTiO}_{3}$ substrate by controlling the oxygen atmosphere and prepared $\mathrm{p}-\mathrm{n}$ heterostructure. Furthermore, $\mathrm{p}-\mathrm{BaSnO}_{3}: \mathrm{K} / \mathrm{n}-\mathrm{BaSnO}_{3}: \mathrm{La}$ whole perovskite $\mathrm{p}-\mathrm{n}$ junctions were reported, and results show that they are stable at elevated temperatures (up to $300^{\circ} \mathrm{C}$ ) [141].

With regard to $\mathrm{B}$-site doped materials, researchers substitute tetravalent ions on $\mathrm{B}$-site by trivalent ions to prepare p-type perovskite oxides. $\mathrm{SrTi}_{1-\mathrm{x}} \mathrm{Sc}_{\mathrm{x}} \mathrm{O}_{3}$ is a p-type semiconductor with $\mathrm{Sc}^{3+}$ replacing $\mathrm{Ti}^{4+}$ in $\mathrm{SrTiO}_{3}$. However, the acceptor levels were so deep that the holes were localized [60]. Guo et al. [142] reported In-doped $\mathrm{SrTiO}_{3}$ films to create hole carriers and investigated the optical properties. The average transmittance is up to $80 \%$ in the visible region. For $\mathrm{Al}$-doped $\mathrm{SrSnO}_{3}(\mathrm{Eg}>3.9 \mathrm{eV})$, the transmittance was increased, too [62].

Perovskites $\mathrm{BaSnO}_{3}$ and $\mathrm{BaZrO}_{3}$ doped by trivalent elements $(\mathrm{Ga}, \mathrm{Sc}, \mathrm{In}, \mathrm{Y})$ are able to incorporate oxygen at low temperatures. The hole concentration decreases at elevated temperatures [143]. Wang et al. reported that Y-doped $\mathrm{BaSnO}_{3}$ showed p-type behavior under a

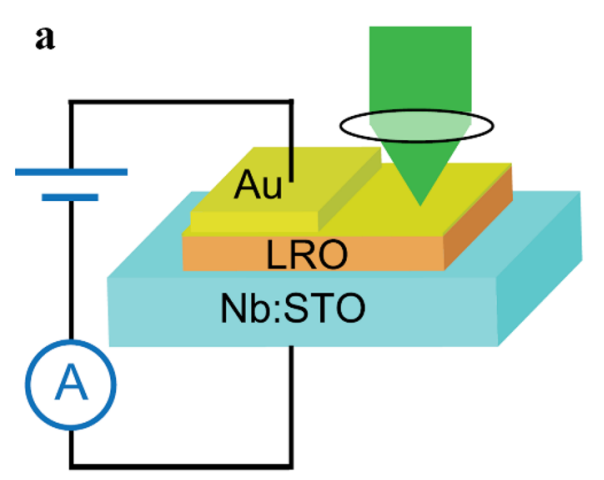

b

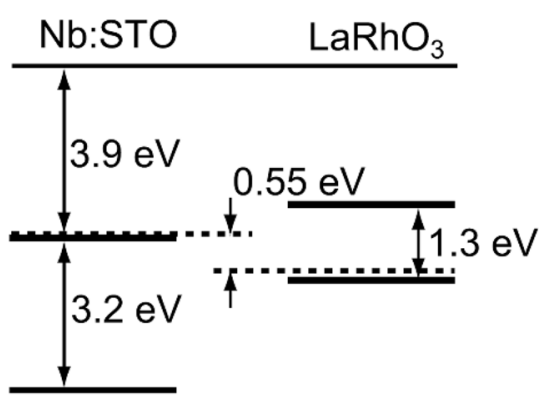

Fig. 4 a Structure of $p-L R O / n-N b: S T O$ heterojunction. b Band alignment relation of LRO and Nb:STO [135] 
controlled atmosphere [144]. It is well known that the electronic conductivity and Seebeck Coefficient of semiconducting materials are measured by high-temperature sintering techniques. These procedures may lead to unreliable results such as changing transport properties from p- to n-type [145]. The holes induced by acceptor-doped perovskite oxides are compensated by intrinsic defects (oxygen vacancies) [146-148]. Acceptor-doped perovskite, $\mathrm{BaSnO}_{3}$, has also gained attention in various electrochemical devices $[149,150]$.

\section{Conclusion and outlook}

In this article, we comprehensively review the recent developments of perovskites with both high carrier concentration and mobility. $\mathrm{SrVO}_{3}$ with strong electron-electron interactions exhibits a higher carrier concentration of $2.2 \times 10^{22} \mathrm{~cm}^{-3}$ than that of ITO. It also maintains a high conductivity of $10^{4} \mathrm{~S} \cdot \mathrm{cm}^{-1}$ and optical transmittance in the visible range by taking advantage of its lower plasma frequency $\left(\omega_{\mathrm{p}}{ }^{*}=1.33 \mathrm{eV}\right)$. The performance of $\mathrm{SrVO}_{3}$ films are affected by crystallinity, mismatched substrate, and growth condition. A low resistivity of $28 \mu \Omega \cdot \mathrm{cm}$ was achieved at room temperature in SVO films, which were grown by hybrid MBE in order to reduce the number of defects. Various lattice matched materials, including $\left(\mathrm{LaAlO}_{3}\right)_{0.3}\left(\mathrm{Sr}_{2} \mathrm{AlTaO}_{6}\right)_{0.7}$ (LSAT), $\mathrm{SrTiO}_{3}$ (STO), and $\mathrm{NdGaO}_{3}$ (NGO) have been used as substrates to prepare SVO films. Meanwhile, the performances of SVO thin films are found sensitive to oxygen pressure. Due to the high effective mass, the carrier mobility is just on the order of $10 \mathrm{~cm}^{2} \cdot \mathrm{V}^{-1} \cdot \mathrm{s}^{-1}$. On the other hand, $\mathrm{BaSnO}_{3}$-based perovskites with dispersive Sn 5 s states on the CBM, leading to a small carrier effective mass, have the highest carrier mobility of $320 \mathrm{~cm}^{2} \cdot \mathrm{V}^{-1} \cdot \mathrm{s}^{-1}$ in the single crystals and $183 \mathrm{~cm}^{2} \cdot \mathrm{V}^{-1} \cdot \mathrm{s}^{-1}$ in the epitaxial films at room temperature. It is easy to substitute $\mathrm{Ba}^{2+}$ by $\mathrm{La}^{3+}$ in $\mathrm{BaSnO}_{3}$ to introduce electron carriers due to the low formation energy of $\mathrm{La}_{\mathrm{Ba}}$. Researchers have also managed to grow LBSO films on lattice matched substrates or insert a buffer layer between the LBSO and the substrate to enhance the carrier mobility. The performance of LBSO film is also affected by oxygen vacancy which could be controlled by depositional condition. Because of the high performance of SVO and LBSO films, they are expected to be excellent candidates of TCOs to further optimize the physical properties.

Moreover, perovskites with chemical and structural stability could be doped on A- or B-site by low valence metal ions to create stable holes in the valence band. Although various acceptor-doped perovskite oxides have been reported, their physical properties are still inferior to the corresponding n-type materials. It is necessary to further optimize the performance of p-type perovskites. Furthermore, perovskite oxides can be doped as both nand p-type conductors, so full perovskite devices might be possible eventually.

\section{Acknowledgements \\ No. \\ Authors' contributions \\ $\mathrm{HH}, \mathrm{ZY}$, and LS planned for this review article. All the authors contributed to the drafting of sections. $H H, Z Y, A S$ and $L S$ revised the manuscript. All authors read and approved the final manuscript.}

\section{Funding \\ Haiying He thanks the support by the National Natural Science Foundation of China (No. 11747090) and the Key Project of Department of Education of Guangdong Province (No. 2016GCZX008). Zhihao Yang thanks the sup- port by the Guangdong Basic and Applied Basic Research Foundation (No. 2019B1515120008)}

\section{Availability of data and materials}

No.

\section{Competing interests}

The authors declare that they have no competing interests.

\section{Author details}

${ }^{1}$ School of Materials Science and Hydrogen Energy, Foshan University, Foshan 528000, China. ${ }^{2}$ Polymer Program, Institute of Materials Science, University of Connecticut, Storrs, CT 06269, USA. ${ }^{3}$ Department of Chemical \& Biomolecular Engineering, University of Connecticut, Storrs, CT 06269, USA.

${ }^{4}$ School of Electronic Information Engineering, Foshan University, Foshan 528000, China.

Received: 8 June 2020 Accepted: 15 September 2020

Published online: 02 October 2020

\footnotetext{
References

1. K. Nomura, H. Ohta, K. Ueda, T. Kamiya, M. Hirano, H. Hosono, Science 300, 1269 (2003)

2. C.G. Granqvist, Sol. Energ. Mat. Sol. C. 91, 1529 (2007)

3. E. Fortunato, D. Ginley, H. Hosono, D.C. Paine, MRS Bull. 32, 242 (2007)

4. D.S. Ginley, C. Bright, MRS Bull. 25, 15 (2000)

5. C.G. Granqvist, A. Hultåker, Thin Solid Films 411, 1 (2002)

6. I. Hamberg, C.G. Granqvist, J. Appl. Phys. 60, R123 (1986)

7. O. Mryasov, A.J. Freeman, Phys. Rev. B 64, 233111 (2001)

8. V. Consonni, G. Rey, H. Roussel, B. Doisneau, E. Blanquet, D. Bellet, Acta Mater. 61, 22 (2013)

9. G. Rey, C. Ternon, M. Modreanu, X. Mescot, V. Consonni, D. Bellet, J. Appl. Phys. 114, 183713 (2013)

10. S.-Y. Lee, B.-O. Park, Thin Solid Films 510, 154 (2006)

11. J. Montero, J. Herrero, C. Guillén, Sol. Energ. Mat. Sol. C. 94, 612 (2010)

12. M. Chen, Z. Pei, C. Sun, J. Gong, R. Huang, L. Wen, Mat. Sci. Eng. B 85, 212 (2001)

13. C. Guillen, J. Herrero, Vacuum 84, 924 (2010)

14. M. Chen, X. Wang, Y. Yu, Z. Pei, X. Bai, C. Sun, R. Huang, L. Wen, Appl. Surf. Sci. 158, 134 (2000)

15. H. Agura, A. Suzuki, T. Matsushita, T. Aoki, M. Okuda, Thin Solid Films 445, $263(2003)$

16. L. Zhang, Y. Zhou, L. Guo, W. Zhao, A. Barnes, H.-T. Zhang, C. Eaton, Y. Zheng, M. Brahlek, H.F. Haneef, Nat. Mater. 15, 204 (2016)

17. P. Erhart, A. Klein, R.G. Egdell, K. Albe, Phys. Rev. B 75, 153205 (2007)

18. L. Li, W. Wang, H. Liu, X. Liu, Q. Song, S. Ren, J. Phys. Chem. C 113, 8460 (2009)

19. Q.-J. Liu, Z.-T. Liu, L.-P. Feng, Comp. Mater. Sci. 47, 1016 (2010)

20. K. Ellmer, Nat. Photonics 6, 809 (2012)
} 
21. A.J. Freeman, K.R. Poeppelmeier, T.O. Mason, R.P. Chang, T.J. Marks, MRS Bull. 25, 45 (2000)

22. F. Tuomisto, V. Ranki, K. Saarinen, D.C. Look, Phys. Rev. Lett. 91, 205502 (2003)

23. A. Janotti, C.G. Van de Walle, Phys. Rev. B 76, 165202 (2007)

24. S. Glöser, L. Tercero Espinoza, C. Gandenberger, M. Faulstich, Resources Policy 44, 35 (2015)

25. T. Minami, Semicond. Sci. Technol. 20, S35 (2005)

26. U.S. Alaan, P. Shafer, A.T. N'Diaye, E. Arenholz, Y. Suzuki, Appl. Phys. Lett. 108, $042106(2016)$

27. M.-L. Lin, J.-M. Huang, C.-S. Ku, C.-M. Lin, H.-Y. Lee, J.-Y. Juang, J. Alloy. Compd. 727, 565 (2017)

28. H. Ohta, H. Hosono, Mater. Today 7, 42 (2004)

29. H. Kawazoe, H. Yanagi, K. Ueda, H. Hosono, MRS Bull. 25, 28 (2000)

30. K.H.L. Zhang, K. Xi, M.G. Blamire, R.G. Egdell, J. Phys.: Condens. Matter 28, $383002(2016)$

31. K. Matsuzaki, K. Nomura, H. Yanagi, T. Kamiya, M. Hirano, H. Hosono, Appl. Phys. Lett. 93, 202107 (2008)

32. M. Snure, A. Tiwari, Appl. Phys. Lett. 91, 092123 (2007)

33. L. Hu, R. Wei, J. Yan, D. Wang, X. Tang, X. Luo, W. Song, J. Dai, X. Zhu, C. Zhang, Adv. Electron. Mater. 4, 1700476 (2018)

34. B. Wang, W. Zhang, K. Yang, T. Liao, F. Li, Y. Cui, Y. Gao, B. Liu, Ceram. Int. 44, 16051 (2018)

35. J. Biscaras, N. Bergeal, A. Kushwaha, T. Wolf, A. Rastogi, R.C. Budhani, J. Lesueur, Nat. Commun. 1, 1 (2010)

36. A. Mercy, J. Bieder, J. Iñiguez, P. Ghosez, Nat. Commun. 8, 1 (2017)

37. I. Grinberg, D.V. West, M. Torres, G. Gou, D.M. Stein, L. Wu, G. Chen, E.M. Gallo, A.R. Akbashev, P.K. Davies, J.E. Spanier, A.M. Rappe, Nature 503, 509 (2013)

38. D.O. Scanlon, Phys. Rev. B 87, 161201 (2013)

39. A. Prakash, P. Xu, A. Faghaninia, S. Shukla, J.W. Ager 3rd, C.S. Lo, B. Jalan, Nat. Commun. 8, 15167 (2017)

40. J. Ravichandran, W. Siemons, H. Heijmerikx, M. Huijben, A. Majumdar, R. Ramesh, Chem. Mater. 22, 3983 (2010)

41. Y. Du, C. Li, K.H.L. Zhang, M.E. McBriarty, S.R. Spurgeon, H.S. Mehta, D. Wu, S.A. Chambers, Appl. Phys. Lett. 111, 063501 (2017)

42. K.H. Zhang, Y. Du, A. Papadogianni, O. Bierwagen, S. Sallis, L.F. Piper, M.E. Bowden, V. Shutthanandan, P.V. Sushko, S.A. Chambers, Adv. Mater. 27, 5191 (2015)

43. J.A. Moyer, C. Eaton, R. Engel-Herbert, Adv. Mater. 25, 3578 (2013)

44. M. Grisolia, J. Varignon, G. Sanchez-Santolino, A. Arora, S. Valencia, M. Varela, R. Abrudan, E. Weschke, E. Schierle, J. Rault, Nat. Phys. 12, 484 (2016)

45. J. Haeni, P. Irvin, W. Chang, R. Uecker, P. Reiche, Y. Li, S. Choudhury, W. Tian, M. Hawley, B. Craigo, Nature 430, 758 (2004)

46. M.A. Riza, M.A. Ibrahim, U.C. Ahamefula, M.A. Mat Teridi, N. Ahmad Ludin, S. Sepeai, K. Sopian, Sol. Energy 137, 371 (2016)

47. E. Moreira, J.M. Henriques, D.L. Azevedo, E.W.S. Caetano, V.N. Freire, E.L. Albuquerque, J. Solid State Chem. 184, 921 (2011)

48. H.-R. Liu, J.-H. Yang, H.J. Xiang, X.G. Gong, S.-H. Wei, Appl. Phys. Lett. 102, 112109 (2013)

49. Q. Liu, J. Liu, B. Li, H. Li, G. Zhu, K. Dai, Z. Liu, P. Zhang, J. Dai, Appl. Phys. Lett. 101, 241901 (2012)

50. E. Baba, D. Kan, Y. Yamada, M. Haruta, H. Kurata, Y. Kanemitsu, Y. Shimakawa, J. Phys. D Appl. Phys. 48, 455106 (2015)

51. H.J. Kim, U. Kim, H.M. Kim, T.H. Kim, H.S. Mun, B.-G. Jeon, K.T. Hong, W.-J. Lee, C. Ju, K.H. Kim, Appl. Phys. Express 5, 061102 (2012)

52. H.J. Kim, U. Kim, T.H. Kim, J. Kim, H.M. Kim, B.-G. Jeon, W.-J. Lee, H.S. Mun, K.T. Hong, J. Yu, Phys. Rev. B 86, 165205 (2012)

53. R. Perez-Casero, J. Perriere, A. Gutierrez-Llorente, D. Defourneau, E. MilIon, W. Seiler, L. Soriano, Phys. Rev. B 75, 165317 (2007)

54. H.M.I. Jaim, S. Lee, X. Zhang, I. Takeuchi, Appl. Phys. Lett. 111, 172102 (2017)

55. W.J. Lee, H.J. Kim, J. Kang, D.H. Jang, T.H. Kim, J.H. Lee, K.H. Kim, Annu. Rev. Mater. Res. 47, 391 (2017)

56. W.J. Lee, H.J. Kim, E. Sohn, H.M. Kim, T.H. Kim, K. Char, J.H. Kim, K.H. Kim Phys. Status Solidi A 212, 1487 (2015)

57. K.G. Rana, V. Khikhlovskyi, T. Banerjee, Appl. Phys. Lett. 100, 213502 (2012)
58. M. Choi, A.B. Posadas, C.A. Rodriguez, A. O'Hara, H. Seinige, A.J. Kellock, M.M. Frank, M. Tsoi, S. Zollner, V. Narayanan, J. Appl. Phys. 116, 043705 (2014)

59. H.H. Wang, F. Chen, S.Y. Dai, T. Zhao, H.B. Lu, D.F. Cui, Y.L. Zhou, Z.H. Chen, G.Z. Yang, Appl. Phys. Lett. 78, 1676 (2001)

60. T. Higuchi, T. Tsukamoto, S. Yamaguchi, K. Kobayashi, N. Sata, M. Ishigame, S. Shin, Nucl. Instrum. Meth. B 199, 255 (2003)

61. J.N. Yun, Z.Y. Zhang, Acta Phys. Chim. Sin. 26, 751 (2010)

62. L.B. Amor, B. Belgacem, J.S. Filhol, M.L. Doublet, M.B. Yahia, R.B. Hassen, Chem Commun 56, 2566 (2020)

63. K.H.L. Zhang, Y. Du, P.V. Sushko, M.E. Bowden, V. Shutthanandan, S. Sallis, L.F.J. Piper, S.A. Chambers, Phys Rev B 91, 155129 (2015)

64. K. Iwashina, A. Kudo, J Am Chem Soc 133, 13272 (2011)

65. A. Kubacka, M. Fernández-García, G. Colón, Chem. Rev 112, 1555 (2012)

66. I.A. Nekrasov, K. Held, G. Keller, D.E. Kondakov, T. Pruschke, M. Kollar, O.K. Andersen, V.I. Anisimov, D. Vollhardt, Phys Rev B 73, 155112 (2006)

67. I. Nekrasov, G. Keller, D. Kondakov, A. Kozhevnikov, T. Pruschke, K. Held, D. Vollhardt, V. Anisimov, Phys Rev B 72, 155106 (2005)

68. M. Karolak, T. Wehling, F. Lechermann, A. Lichtenstein, J Phys Condens. Matter 23, 085601 (2011)

69. M. Casula, A. Rubtsov, S. Biermann, Phys. Rev. B 85, 035115 (2012)

70. H. Lee, K. Foyevtsova, J. Ferber, M. Aichhorn, H.O. Jeschke, R. Valenti, Phys. Rev. B 85, 165103 (2012)

71. T. Yoshida, M. Hashimoto, T. Takizawa, A. Fujimori, M. Kubota, K. Ono, H. Eisaki, Phys. Rev. B 82, 085119 (2010)

72. K. Yoshimatsu, K. Horiba, H. Kumigashira, T. Yoshida, A. Fujimori, M. Oshima, Science 333, 319 (2011)

73. S. Aizaki, T. Yoshida, K. Yoshimatsu, M. Takizawa, M. Minohara, S. Ideta, A. Fujimori, K. Gupta, P. Mahadevan, K. Horiba, Phys. Rev. Lett. 109, 056401 (2012)

74. B. O'Connor, C. Haughn, K.-H. An, K.P. Pipe, M. Shtein, Appl. Phys. Lett. 93, 223304 (2008)

75. K.R. Poeppelmeier, J.M. Rondinelli, Nat. Mater. 15, 132 (2016)

76. M. Mirjolet, F. Sánchez, J. Fontcuberta, Adv. Funct. Mater. 29, 1808432 (2019)

77. J. Wang, G. Rijnders, G. Koster, Appl. Phys. Lett. 113, 223103 (2018)

78. A. Boileau, A. Cheikh, A. Fouchet, A. David, C. Labbé, P. Marie, F. Gourbilleau, U. Lüders, Adv. Opt. Mater. 7, 1801516 (2019)

79. B. Bérini, V. Demange, M. Bouttemy, E. Popova, N. Keller, Y. Dumont, A. Fouchet, Adv. Mater. Interf. 3, 1600274 (2016)

80. A. Boileau, A. Cheikh, A. Fouchet, A. David, R. Escobar-Galindo, C. Labbe, P. Marie, F. Gourbilleau, U. Lüders, Appl. Phys. Lett. 112, 021905 (2018)

81. L. Shoham, M. Baskin, M.G. Han, Y. Zhu, L. Kornblum, Adv. Electron. Mater. 6, 1900584 (2020)

82. M. Brahlek, L. Zhang, C. Eaton, H.-T. Zhang, R. Engel-Herbert, Appl. Phys. Lett. 107, 143108 (2015)

83. C. Eaton, J.A. Moyer, H.M. Alipour, E.D. Grimley, M. Brahlek, J.M. LeBeau, R. Engel-Herbert, J. Vac. Sci. Thechn. A 33, 061504 (2015)

84. D.H. Jung, H.S. So, H. Lee, J. Vac. Sci. Thechn. A 37, 021507 (2019)

85. A. Kumar, S. Maurya, S. Chawla, S. Patwardhan, B. Kavaipatti, Appl. Phys. Lett. 114, 212103 (2019)

86. H.N. Lee, H.M. Christen, M.F. Chisholm, C.M. Rouleau, D.H. Lowndes, Appl. Phys. Lett. 84, 4107 (2004)

87. G. Rijnders, D.H. Blank, J. Choi, C.-B. Eom, Appl. Phys. Lett. 84, 505 (2004)

88. B. Berini, W. Noun, Y. Dumont, E. Popova, N. Keller, J. Appl. Phys. 101, 023529 (2007)

89. M. Orita, H. Ohta, M. Hirano, S. Narushima, H. Hosono, Philosophical Magazine B 81, 501 (2001)

90. H. Yabuta, M. Sano, K. Abe, T. Aiba, T. Den, H. Kumomi, K. Nomura, T. Kamiya, H. Hosono, Appl. Phys. Lett. 89, 112123 (2006)

91. H. Mizoguchi, H.W. Eng, P.M. Woodward, Inorg. Chem. 43, 1667 (2004)

92. C. Park, U. Kim, C.J. Ju, J.S. Park, Y.M. Kim, K. Char, Appl. Phys. Lett. 105, $203503(2014)$

93. J. Shin, Y.M. Kim, Y. Kim, C. Park, K. Char, Appl. Phys. Lett. 109, 262102 (2016)

94. U. Kim, C. Park, T. Ha, Y.M. Kim, N. Kim, C. Ju, J. Park, J. Yu, J.H. Kim, K. Char, APL mater. 3, 036101 (2015)

95. Y.M. Kim, C. Park, U. Kim, C. Ju, K. Char, Appl. Phys. Express 9, 011201 (2015)

96. K. Krishnaswamy, L. Bjaalie, B. Himmetoglu, A. Janotti, L. Gordon, C.G.V.d. Walle, Appl. Phys. Lett. 108, 083501 (2016) 
97. K. Fujiwara, K. Nishihara, J. Shiogai, A. Tsukazaki, Appl. Phys. Lett. 110, 203503 (2017)

98. J. Yue, A. Prakash, M.C. Robbins, S.J. Koester, B. Jalan, A.C.S. Appl, Mater. Inter. 10, 21061 (2018)

99. A.V. Sanchela, T. Onozato, B. Feng, Y. Ikuhara, H. Ohta, Phys. Rev. Mater. 1, $034603(2017)$

100. B.G. Kim, J.Y. Jo, S.W. Cheong, J. Solid State Chem. 197, 134 (2013)

101. S. Dabaghmanesh, R. Saniz, M.N. Amini, D. Lamoen, B. Partoens, J. Phys.: Condens. Matter 25, 415503 (2013)

102. B. Monserrat, C.E. Dreyer, K.M. Rabe, Phys. Rev. B 97, 104310 (2018)

103. W. Wunderlich, H. Ohta, K. Koumoto, Physica B 404, 2202 (2009)

104. D.M. Riffe, JOSA B 19, 1092 (2002)

105. F. Simonis, M. Van Der Leij, C. Hoogendoorn, Sol. Ene. Mater. 1, 221 (1979)

106. E. Moreira, J.M. Henriques, D.L. Azevedo, E.W.S. Caetano, V.N. Freire, U.L. Fulco, E.L. Albuquerque, J. Appl. Phys. 112, 043703 (2012)

107. L. Weston, L. Bjaalie, K. Krishnaswamy, C. Van de Walle, Phys. Rev. B 97, $054112(2018)$

108. X. Luo, Y.S. Oh, A. Sirenko, P. Gao, T.A. Tyson, K. Char, S.W. Cheong, Appl. Phys. Lett. 100, $172112(2012)$

109. H. Mun, U. Kim, H.M. Kim, C. Park, T.H. Kim, H.J. Kim, K.H. Kim, K. Char, Appl. Phys. Lett. 102, 252105 (2013)

110. K. Miura, D. Kiriya, T. Yoshimura, A. Ashida, N. Fujimura, Phys. Status Solidi A 216, 1700800 (2019)

111. P.V. Wadekar, J. Alaria, M. O'Sullivan, N.L.O. Flack, T.D. Manning, L.J. Phillips, K. Durose, O. Lozano, S. Lucas, J.B. Claridge, M.J. Rosseinsky, Appl. Phys. Lett. 105, 052104 (2014)

112. S. Raghavan, T. Schumann, H. Kim, J.Y. Zhang, T.A. Cain, S. Stemmer, APL Mater. 4, 016106 (2016)

113. Z. Lebens-Higgins, D.O. Scanlon, H. Paik, S. Sallis, Y. Nie, M. Uchida, N.F. Quackenbush, M.J. Wahila, G.E. Sterbinsky, D.A. Arena, J.C. Woicik, D.G. Schlom, L.F.J. Piper, Phys. Rev. Lett. 116, 027602 (2016)

114. H. Paik, Z. Chen, E. Lochocki, A. Seidner H, A. Verma, N. Tanen, J. Park, M. Uchida, S. Shang, B.-C. Zhou, APL Mater. 5, 116107 (2017)

115. W.-J. Lee, H.J. Kim, E. Sohn, T.H. Kim, J.-Y. Park, W. Park, H. Jeong, T. Lee, J.H. Kim, K.-Y. Choi, K.H. Kim, Appl. Phys. Lett. 108, 082105 (2016)

116. J. Shiogai, K. Nishihara, K. Sato, A. Tsukazaki, AIP Adv. 6, 065305 (2016)

117. Z. Wang, H. Paik, Z. Chen, D.A. Muller, D.G. Schlom, APL Mater. 7, 022520 (2019)

118. A.V. Sanchela, M. Wei, J. Lee, G. Kim, H. Jeen, B. Feng, Y. Ikuhara, H.J. Cho, H. Ohta, J. Mater. Chem. C 7, 5797 (2019)

119. A. Tiwari, M.S. Wong, Thin Solid Films 703, 137986 (2020)

120. D. Yoon, S. Yu, J. Son, NPG Asia Mater. 10, 363 (2018)

121. Q. Liu, J. Dai, Y. Zhang, H. Li, B. Li, Z. Liu, W. Wang, J. Alloy. Compd. 655 , 389 (2016)

122. I.A. Alagdal, A.R. West, J. Mater. Chem. C 4, 4770 (2016)

123. S. Yu, D. Yoon, J. Son, Appl. Phys. Lett. 108, 262101 (2016)

124. K. Ganguly, A. Prakash, B. Jalan, C. Leighton, APL Mater. 5, 056102 (2017)

125. K. Ganguly, P. Ambwani, P. Xu, J.S. Jeong, K.A. Mkhoyan, C. Leighton, B. Jalan, APL Mater. 3, 062509 (2015)
126. H.J. Cho, T. Onozato, M. Wei, A. Sanchela, H. Ohta, APL Mater. 7, 022507 (2019)

127. G. Hautier, A. Miglio, G. Ceder, G.-M. Rignanese, X. Gonze, Nat. Commun. 4, 2292 (2013)

128. R. Woods-Robinson, D. Broberg, A. Faghaninia, A. Jain, S.S. Dwaraknath, K.A. Persson, Chem. Mater. 30, 8375 (2018)

129. J.L. Lyons, A. Janotti, C.G.V.d. Walle, Appl. Phys. Lett. 95, 252105 (2009)

130. J.C. Fan, K.M. Sreekanth, Z. Xie, S.L. Chang, K.V. Rao, Prog. Mater Sci. 58, 874 (2013)

131. B.S. Li, K. Akimoto, A. Shen, J. Cryst. Growth 311, 1102 (2009)

132. K. Ueda, S. Inoue, S. Hirose, H. Kawazoe, H. Hosono, Appl. Phys. Lett. 77, $2701(2000)$

133. S. Narushima, H. Mizoguchi, K.-I. Shimizu, K. Ueda, H. Ohta, M. Hirano, T. Kamiya, H. Hosono, Adv. Mater. 15, 1409 (2003)

134. T. Nakamura, T. Shimura, M. Itoh, Y. Takeda, J. Solid State Chem. 103, 523 (1993)

135. M. Nakamura, Y. Krockenberger, J. Fujioka, M. Kawasaki, Y. Tokura, Appl. Phys. Lett. 106, 072103 (2015)

136. H. Kawazoe, M. Yasukawa, H. Hyodo, M. Kurita, H. Yanagi, H. Hosono, Nature 389, 939 (1997)

137. E. Arca, K. Fleischer, I.V. Shvets, Appl. Phys. Lett. 99, 111910 (2011)

138. L. Hu, M. Zhao, S. Liang, D. Song, R. Wei, X. Tang, W. Song, J. Dai, G. He, C. Zhang, Phys. Rev. Appl. 12, 044035 (2019)

139. H. Takashima, N. Kikuchi, H. Kawanaka, K. Tonooka, Y. Aiura, Appl. Surf. Sci. 422, 869 (2017)

140. M. Imada, A. Fujimori, Y. Tokura, Rev. Mod. Phys. 70, 1039 (1998)

141. H.M. Kim, U. Kim, C. Park, H. Kwon, K. Char, Apl Mater. 4, 056105 (2016)

142. H. Guo, L. Liu, Y. Fei, W. Xiang, H. Lü, S. Dai, Y. Zhou, Z. Chen, J. Appl. Phys. 94, 4558 (2003)

143. E. Bévillon, G. Dezanneau, G. Geneste, Physical Review B 83, 174101 (2011)

144. Y. Wang, A. Chesnaud, E. Bevillon, G. Dezanneau, Solid State lonics 214, 45 (2012)

145. S. Singh, P. Singh, O. Parkash, D. Kumar, Adv. Appl. Ceram. 106, 231 (2007)

146. A. Zunger, Appl. Phys. Lett. 83, 57 (2003)

147. J. Robertson, S.J. Clark, Physical Review B 83, 075205 (2011)

148. D.O. Scanlon, G.W. Watson, J. Mater. Chem. 22, 25236 (2012)

149. S. Choi, C.J. Kucharczyk, Y. Liang, X. Zhang, I. Takeuchi, H.-I. Ji, S.M. Haile, Nature Energy 3, 202 (2018)

150. L.P. Putilov, A.K. Demin, V.I. Tsidilkovski, P. Tsiakaras, Appl. Energy 242 $1448(2019)$

\section{Publisher's Note}

Springer Nature remains neutral with regard to jurisdictional claims in published maps and institutional affiliations.

\section{Submit your manuscript to a SpringerOpen ${ }^{\circ}$ journal and benefit from:}

- Convenient online submission

- Rigorous peer review

- Open access: articles freely available online

- High visibility within the field

- Retaining the copyright to your article

Submit your next manuscript at springeropen.com 